\title{
Neonatal Mortality And Associated Factors In A Pastoral Region, Afar, Ethiopia: A Health Facility Based Study
}

Abay Woday ( $\sim$ abaywoday@yahoo.com )

Samara University https://orcid.org/0000-0003-0499-4690

\section{Yohannes Mekuria}

Samara University, Afar, Ethiopia

Christine St Denis

Hospital for Sick Children

Research article

Keywords: Neonatal mortality, associated factors, Afar region, Ethiopia

Posted Date: August 15th, 2019

DOl: https://doi.org/10.21203/rs.2.12946/v1

License: (c) (i) This work is licensed under a Creative Commons Attribution 4.0 International License.

Read Full License 


\section{Abstract}

Abstract Background: Neonatal mortality is public health issue in developing countries, such as Ethiopia. Unfortunately, the issue is noticeably under-reported and underestimated, so the true gravity of the situation cannot be acknowledged. Subsequently, Afar in Ethiopia contributes the largest burden of underfive mortality when compared to other regions in the country. Regrettably, there is no current information to the rates and predictors of neonatal mortality for the region. Thus, this study aims to assess neonatal mortality and associated factors in pastoral communities residing in Afar, Ethiopia. Methods: A health facility based retrospective cross sectional study was conducted on 403 neonates admitted to the neonatal intensive care unit (NICU) from May 1 st 2015 - May 2nd 2019. Medical records were reviewed and audited for both mothers and neonates to collect data using standardized data extraction checklist. The medical records were selected using a systematic random sampling technique. Binary logistic regression with odds ratio and $95 \%$ Confidence interval was calculated to assess the association between neonatal mortality and associated factors. Finally, the statistical significance level was declared at a pvalue $<0.05$. Results: 391 medical records of newborns were included with data complete rate of $97.02 \%$. The prevalence of neonatal mortality was $14.6 \%$ (95\% Cl 11.0\%-18.4\%). Lack of antenatal care (ANC) follow up $(\mathrm{AOR}=4.69: 95 \% \mathrm{Cl} 1.77,12.47)$, giving birth through cesarean section $(\mathrm{AOR} 3.59,95 \% \mathrm{Cl} 1.22$, 10.55), having a temperature less than 36.5 o $C$ within the first hour of admission (AOR $10.75,95 \% \mathrm{Cl}$ $3.75,30.80)$, perinatal asphyxia (AOR $7.16,95 \% \mathrm{Cl} 2.22,23.10)$ and/or having a length of stay greater than five days in the hospital (AOR $0.23,95 \% \mathrm{Cl} 0.08,0.66)$ were significantly associated with neonatal mortality. Conclusion: This study revealed that the rate of neonatal mortality is still too high compared to the national data. Antenatal care, cesarean section delivery, length of stay in the hospital, low temperature with in the first hour of admission and perinatal asphyxia were factors associated with neonatal mortality. Thus, the health facilities should give due attention for improving antenatal cares, intra-partum cares and standardized cares for admitted neonates. Additional prospective studies are recommended.

\section{Background}

The World Health Organization (WHO) defines neonates as live-born infants whose age is within 28 complete days of birth [1]. Neonatal mortality (NM) is defined as infant death, which occurred during the first four weeks after birth [2]. From this, neonatal deaths are subdivided into early neonatal death (death of a live-born infant during the first seven complete days of life) and late neonatal death (death of a liveborn infant after 7 complete days but before 28 complete days of life) [1, 3].

By the end of 2018, an estimated 5.4 million of children died before their $5^{\text {th }}$ birthday worldwide and more than 2.5 million neonatal deaths happened in the same year which accounted of $47 \%$ of under-five deaths. However, the highest rates of child mortality are still found in sub-Saharan Africa (i.e. 2.7 million children). In addition, sub-Saharan Africa has the highest risk of death in the first month of life and is among the regions showing the least progress [4]. Consequently, the burden of neonatal mortality has not declined in the needed manner that was hoped for, which were set out by the Sustainable Development Goals. 
Different strategies, policies and programs have been implemented in the past to aid in the reduction of neonatal mortality at global, national and regional levels, such as the development of the fourth Millennium Development Goals (MDG) [5]. Recently, the Sustainable Development Goal (SDGs) were launched, which have thirteen specific targets. Of these goals, there are two specific targets, which focus on the reduction of neonatal mortality rates (NMR) [20 per 100 live births to 12 per 1000 live births] and under-five mortality rates (U5MR) [42.5 per 1000 live births to 25 per 1000 live-births] at the end of 2030 $[6,7]$. Every newborn: progress, priority and survival strategy [8] were some of the strategies and policies designed at global level. Subsequently, in Ethiopia, the Federal Ministry of Health developed a national strategy for addressing community maternal and neonatal health. in which National Scoping to increase the demand, accesses and use of Community based maternal and neonatal health services those were implemented with the primary health care approach implemented since 1978 and the health extension packages since 1990s $[9,10]$. Moreover, newborn's health was deemed one of Ethiopia's top priorities in the past ten years and, still is, in the current 2016-2020 Health Sector Transformation Plan. The country also designed the newly revised child survival and newborn care strategy $[3,5,11,12]$.

Even though developing nations, such as Ethiopia, have made progress in the reduction of under-five mortality rates by more than fifty percent at the end of 2015 , the neonatal mortality rates have still not reduced enough $[7,13]$. In addition, over $67 \%$ of neonatal deaths in Ethiopia are mainly due to preventable causes such as extreme maternal age, prematurity, low-birth-weight, newborn infections, short birth space, birth asphyxia and/or birth trauma [14-17]. Birth asphyxia, neonatal infections and prematurity are the three leading causes of neonatal mortality accounting for $93 \%$ of deaths in the first month of life [18]. Moreover, a prospective cohort study conducted in Butajira district, south central Ethiopia and a study conducted in Gondar referral hospital found that more than $70 \%$ of neonatal deaths occurred during the early neonatal period ( $0-6$ days) and more than $30 \%$ were in the late neonatal period (7-27 days). Of the total number of neonatal mortality, $54 \%$ occurred in the first 24 hours of life $[19,20]$

In 2018, in Ethiopia, the rate of neonatal mortality ranges between 23.4 per 1000 live births to 44 per 1000 live births [21-24]. In 2016, though the rate of neonatal mortality decreased from 54 to 29 per 1000 live births at national level, the Afar regional state has the second highest neonatal mortality rate (38 per 1000 live births) next to the Amhara regional state [23]. From this, it can be seen that neonatal mortality is still a public health problem in Ethiopia and the problem is expected to be higher in pastoral communities, where there is no evidence-based studies besides the national survey.

Finally, there are no specific studies conducted to assess the burden and contributing factors for neonatal mortality in the pastoral communities within the Afar region. Therefore, this study intends to assess the prevalence of neonatal mortality and its associated factors in this region and, hopefully, will generate evidence that will help to develop different strategies to reduce the burden of neonatal mortality in regional and national levels.

\section{Methods}


Study settings and participants

An institution based five years retrospective cross-sectional study (i.e. $1^{\text {st }}$ May 2015 up to $2^{\text {nd }}$ May 2019) was conducted from $1^{\text {st }}$ May to $2^{\text {nd }}$ June 2019 to assess neonatal mortality rates and associated factors among neonates admitted in randomly selected public hospitals (Dubti referral and Aysaita district hospitals) found in Afar, Ethiopia. The hospitals are located $598 \mathrm{kms}$, and $658 \mathrm{kms}$ away from the capital city, Addis Ababa, respectively. Annually, these hospitals serve more than a half million people.

All systematically selected neonates who were admitted in the randomly selected government hospitals' neonatal intensive care unit from $1^{\text {st }}$ May $2015-2^{\text {nd }}$ May 2019 and those who had a complete medical record were included in the study. However, all neonates who had no discharge summary note and confirmed stillbirths were excluded from this study.

The sample size was calculated using a single population proportion formula. In order to have an adequate sample size, we have taken $P=50 \%$ with the basic assumptions of $95 \%$ confidence interval (the Critical value $\mathrm{Za} / 2=1.96), 5 \%$ margin of error and the researchers added $5 \%$ to compensate the incomplete data. Then, the calculated sample size became $403(384 \times 0.05+384)$.

$$
n=\frac{(Z a / 2)^{2}(P)(1-P)}{d^{2}}=384
$$

Where: $\mathbf{n}=$ the required sample size, $\mathbf{Z} \mathbf{a} / \mathbf{2}=$ the standardized normal distribution curve value for the $95 \%$ confidence interval, $\mathbf{P}=$ the proportion of neonatal mortality among the general newborns, and $\mathbf{d}=$ degree of precision (the margin of error between the sample and population).

The two public hospitals were randomly selected from five hospitals found in Afar regional state. The medical records of the admitted newborns were selected using a systematic sampling technique with every $5^{\text {th }}$ interval (i.e. from 2,015 total medical records in the last five years). The sample was proportionally allocated for each hospitals. The index medical record of newborn was selected using a lottery method from 1-5. Thus, the study participants were recruited using the $3^{\text {rd }}, 8^{\text {th }}, 13^{\text {th }}, 18^{\text {th }}, \ldots$ until the required sample size was satisfied based on the inclusion criteria.

\section{Data collection tools and procedures}

The data extraction checklist was developed after reviewing of the NICU admission and delivery registration log books. The chart review checklist included sociodemographic characteristics, maternal factors (age, ANC follow up, mode of delivery, place of delivery, maternal HIV status, parity, multiple delivery, gravidity), fetal factors (sex, birth weight, status at birth, diagnosis of disease, gestational age, APGAR scores at birth, neonates HIV status) and health care providers related factors (medication given at admission, vital signs taken at admission, scheduled prescribed medications). 
Training was provided over two days for data collectors and supervisors. The checklist was pretested on $5 \%$ of the samples at non-selected public hospitals, where a panel of experts verified content validity of the instruments, and the required revisions were made.

Data was collected by trained midwifes using a standardized and structured reviewer administered checklist.

\section{Definitions:}

Completed data: a data that has at least complete discharge summary about the admitted neonate including possible cause of death

Neonate: a new born baby within 28 days of life.

Neonatal mortality: the death of an infant that happened after birth but before 28 days of life.

Still birth: neonate born without evidence of life at birth.

\section{Data processing and management}

Data collected was cleaned for errors, entered into Epi-Data version 3.1 and exported into SPSS version 23.0 for statistical analysis. Descriptive statistics were done and the results were presented with texts, tables, mean and standard deviation.

A bivariate logistic regression analysis was done to identify variables that had a $p<0.25$ to be considered in the multivariable logistic regression model. Correlation between independent variables was checked. The model fitness was assessed. Multivariable logistic regression analysis was done to identify factors associated with neonatal mortality. The findings of the final model were reported with an odds ratios (OR) and corresponding $95 \%$ Confidence Interval. Finally, a statistically significant level was declared at a $p$ $<0.05$ in the final regression model.

\section{Results}

Study Participants Sociodemographic Characteristics

A total of 391 neonatal charts were reviewed and $97 \%$ fulfilled the completeness criteria. In this study, it was found that $251(64.2 \%)$ of the neonates were males. In addition, the majority of neonates [317 (81.1\%)] were admitted into the neonatal intensive care unit (NICU) at less than 7 days of age. The mean age of mothers was 26.05 (SD \pm 5.35$)$ and $321(82.1 \%)$ of mothers resided in urban areas (see Table 1).

Maternal health related conditions 
The maternal chart review revealed that more than two thirds of the mothers [239 (68.7\%)] had four or more ANC visits during their pregnancy. On the other hand, only $43(11 \%)$ of mothers had no ANC follow up at all. Moreover, the majority of $346(88.5 \%)$ the mothers born the current neonates in health institutions and $328(83.9 \%)$ of the mothers gave birth through spontaneously vaginal delivery. Furthermore, $284(72.6 \%)$ of mothers had a history of multipara and only $27(6.9 \%)$ of them had multiple delivery. Finally, 13 (3.3\%) of mothers had known recorded medical illnesses during pregnancy (see Table 2).

Fetal health related conditions

The neonatal chart review found that $92(23.5 \%)$ of neonates were preterm and $118(30.2 \%)$ of the neonates had a birth weight less than $2.5 \mathrm{~kg}$. In addition, $270(69.1 \%)$ of the neonates had a resuscitation event at birth and only $10(2.6 \%)$ of the admitted neonates were retroviral infection exposed. Moreover, the study identified the leading causes of neonatal admission in the NICU. The leading causes of admission were; early onset neonatal sepsis (43.5\%), low birth weight $(27.1 \%)$ and prematurity $(23.5 \%)$ (See Table 3).

Cares given for neonates immediately after admission

It was found that the majority of neonates were given antibiotics within one hour of admission 372 (95.1\%) and 355 (90.8\%) of the neonates were given IV fluids containing glucose. In addition, 310 (79.3\%) of neonates were supplemented with oxygen and 12 (3.1\%) of admitted neonates were given phototherapy. Here, we reassured that one neonate may be given more than one care immediately after admission. Such as, antibiotics and IV fluid or oxygen and antibiotics and so on (see Figure 1).

Neonatal outcomes at discharge and causes of neonatal mortality

This study revealed that the overall prevalence of neonatal mortality was $14.6 \%(95 \% \mathrm{Cl}: 11.0,18.4)$. Moreover, the neonatal mortality rate was 35.1 per 1000 live births in the selected NICUs. When we look the five years trend of neonatal mortality, it is still steadily increasing from 2015 to 2019 (17.5\% to $29.8 \%)$. In addition, 300 (76.7\%) of the neonates were discharged within 5 days of admission and the mean length of stay in NICUs was 4.16 days \pm 3.07 SD. Furthermore, the study showed that the leading causes of neonatal mortality were prematurity $(43.9 \%)$, early onset neonatal sepsis (35.1\%), low birth weight (33.4\%) and perinatal asphyxia (21.1\%) (See Table 4).

Factors associated with neonatal mortality

After checking for model multi-collinearity and model fitness, variables with a p-value $<0.25$ were entered into the final model. The multivariable logistic regression analysis showed that lack of ANC follow up, giving birth through cesarean section, having a temperature less than $36.5^{\circ} \mathrm{C}$ at the first hour of admission, perinatal asphyxia (PNA) and length of stay in the NICU for less than five days after admission were the independent predictors of neonatal mortality. 
Neonates born from mothers who did not receive ANC follow up during pregnancy had 4.7 times the greater risk of death compared to neonates born from mothers who had ANC follow up (AOR=4.69: $95 \% \mathrm{Cl}$ $1.77,12.47)$. The odds of neonatal mortalities among neonates born through cesarean section was 3.6 times greater compared to neonates born through spontaneous vaginal delivery $(A O R=3.59: 95 \% \mathrm{Cl} 1.22$, 10.55). Neonates who had PNA at admission had 7.1 times risk of death compared to those did not have PNA (AOR=7.16: $95 \% \mathrm{Cl} 2.22,23.10)$. The odds of neonatal death among neonates who had a body temperature less than 36.5 at the $1^{\text {st }}$ hour of admission was 10.7 times higher compared to neonates who had a normal body temperature $(A O R=10.75: 95 \% \mathrm{Cl} 3.75,30.80)$. Furthermore, neonates stayed for five or more days at NICU were $77 \%$ less likely to die compared to neonates who stayed for less than five days (AOR=0.23: 95\% Cl 0.08, 0.66) (see Table 5).

\section{Discussion}

In developing countries like Ethiopia, rates of neonatal mortality are several folds higher compared to developed nations, ranging ranges between 23.4 per 1000 live births to 44 per 1000 live births [21-24]. However, accurate epidemiological data is not adequate, and the exact magnitude neonatal mortality in pastoral communities of Ethiopia is not clearly known. Thus, this study aimed to assess the prevalence and associated factors of neonatal mortality in pastoral communities of Ethiopia, within the Afar region. Prevalence of neonatal mortality in the Afar region were high compared to the national mortality figure. The multivariable logistic regression found that the lack of ANC follow up, neonates delivered by caesarean section, neonates who had a body temperature of less than $36.5 \mathrm{C}$ at the first hour of admission, neonates who stayed less than five days in the NICU and neonates with PNA were all the independent predictors of neonatal mortality in the Afar region.

Moreover, the prevalence of neonatal mortality was found to be $14.6 \%(95 \% \mathrm{Cl}: 11.0,18.4)$. This finding is similar with a study conducted in Gondar university teaching hospital, Northwest Ethiopia (14.3\%) [20] and a retrospective chart review done in Felege Hiwot referral hospital, Bahir Dar (13.3\%) [25]. But, the finding is higher than the prevalence of neonatal mortality reported in the Somali region, Ethiopia (5.7\%) [26], a study done in Jimma zone, Southwest Ethiopia (3.2\%) [18], a study done in North Gondar, Northwest Ethiopia (4.4\%) [22], and a study done in Ayder referral hospital, Mekelle (6.6\%) [17]. The difference could be explained by methodological differences among studies and dissimilarity in sociocultural elements such as health service utilization, difference in hospital settings (equipment available and skilled persons), economical variations among study participants of the study areas as well as a difference in geographical locations.

On the other hand, the prevalence of neonatal mortality in this study is lower than a study conducted in Mizan Tepi university teaching hospital (22.8\%) [21], and a study conducted in Gondar university teaching hospital (23.1\%) [16]. The variations may be justified by increased awareness of the community upon utilization of available health services including delivery at health facilities, and seeking health facilities for sick neonates and children. 
Furthermore, it was found that the identified major causes of neonatal mortality were prematurity (43.9\%), early onset neonatal sepsis (35.1\%), perinatal asphyxia (PNA) and low birth weight (21.1\%). This is similar with a study conducted in Mizan Tepi university teaching hospital having prematurity (31\%), neonatal sepsis (29.7\%), low birth weight (15.3\%) and PNA (7.7\%) as the leading causes of death [21]. This could be explained by the majority of neonatal deaths in developing countries are related to conditions of labor, intrapartum and the immediate newborn care practices. From this, it can be seen that neonatal survival interventions are not targeting the intrapartum as well as immediate and early neonatal periods, and as a direct result, neonatal mortality has not declined in the needed manner.

The multivariable logistic regression analysis showed that neonatal mortality was significantly associated with lack antenatal care follow up. The rate of neonatal mortality was 4.7 times greater among mothers who did not have ANC follow up compared to those mothers had ANC follow up (AOR $4.69,95 \% \mathrm{Cl} 1.77,12.47)$. This finding is similar with a study conducted in North Shoa zone, Amhara region [27], and a study conducted in Jimma zone, Southwest Ethiopia [18]. This can be explained by the fact that women not having antenatal care follow up during pregnancy are more at risk for prone pregnancy and intrapartum related problems, which in turn, can put the newborn at risk of death. Therefore, women with adequate antenatal care visits have a better chance of early detection and management of the birth related problems.

Additionally, it was found that neonatal mortality was related to the hospital length of stay. Neonates who stayed for more than 5 days in the neonatal intensive care unit (NICU) had a $77 \%$ reduction in mortality rates when compared to those who stayed for less than five days (AOR $0.23: 95 \% \mathrm{Cl} 0.08,0.66$ ). This finding is in line with a study conducted in Jimma university medical center which stated that neonates who stayed for less than seven days in the NICU had 3.9 times higher risk of neonatal mortality when compared to those who stayed for seven or more days [28]. This can be explained because most neonatal deaths happen in the early neonatal periods (0-6 days of life) than in the late neonatal period of life (7-28 days) $[19,20]$. Thus, due attention should be given for neonates in the early neonatal period to reduce neonatal mortality in the health facilities.

In addition, this study revealed that the odds of death among neonates who had a body temperature less than $36.5 \mathrm{C}$ at the first hour of admission was 10.7 times greater than compared to those neonates who had a normal body temperature $\left(36.5-37.5^{\circ} \mathrm{C}\right.$ ) (AOR 10.75: $\left.95 \% \mathrm{Cl} 3.75,30.80\right)$. This is consistent with a retrospective cohort study conducted in southern Ethiopia referral hospitals which state that neonates who had a temperature of less than 36.5 at admission had higher risk of death than neonates with normal temperature (36.5 to 37.5) [29]. This can be justified by neonates who are in a hypothermic state may be more prone to different infections. As result, they are more likely to become septic and die when compared to neonates with normal body temperatures.

Moreover, this study found that neonates when delivered by cesarean section were 3.6 times at greater risk of death than neonates born spontaneously by vaginal delivery (SVD) (AOR 3.59: 95\% Cl 1.22, 10.55). This finding is similar with a study conducted at Pakistan, where delivery using C-section had increased 
risk of neonatal mortality [30]. This might be related to neonates born via C-section without clear indications such as prolonged labor, fetal distress, obstructed labor and other medical problems during pregnancy. These neonates delivered through $\mathrm{C}$-section are at greater risk of birth asphyxia than neonates born with birth canal. Therefore, neonates born through C-section had a high probability of death than neonates delivered through the natural birth canal. However, this result is contrary with a study conducted in southern Ethiopia referral hospital NICU, where neonates delivered using C-section had $66 \%$ less chance of risk of death compared to SVD (AOR 0.34: $95 \% \mathrm{Cl} 0.19,0.61$ ) [29]. This can explained by timely decision making rather than simply waiting for vaginal delivery, which may save the life of the neonate and the mother. Thus, delivering through $\mathrm{C}$-section with clear indications can reduce the risk of death by early identification and intervention of birth related complications such as prolonged labor.

Finally, neonates with a history of perinatal asphyxia (PNA) had 7.2 times greater risk of death when compared to those who had no history of PNA. This is consistent with a study conducted in southern Ethiopia referral hospitals [29], which found that neonates with PNA had 2 times higher risk of death than their counterparts. This finding is also similar with a study conducted in Jimma university medical center, which revealed neonates who had a history of birth asphyxia had 5 times greater risk of death [28]. This may be due to the fact that besides commencement of adequate efforts after admission, neonates with respiratory problems like birth asphyxia had a greater risk for a poor prognosis and death compared to neonates admitted with other medical problems. Therefore, neonates with a respiratory distress have higher chance of death when compared to those who do not experience any respiratory distress.

Study limitations: the study was conducted based on patient chart reviews, which may not display all factors pertaining to neonatal mortality. So, the results may not be fully representative of the community's neonatal mortality. In addition, there is a potential to miss neonatal deaths particularly with those whose discharge status were incomplete.

\section{Conclusions}

In conclusion, this study found that there is a high prevalence of neonatal mortality when compared to the national and regional data. The majority of neonatal deaths occurred in the first five days of life with the leading causes due to early onset neonatal sepsis, low birth weight and prematurity.

Neonates born from mothers who did not receive any ANC, delivered by caesarean section, had a body temperature of less than $36.5 \mathrm{C}$ within the first hour of admission, had a length of stay less than five days in the NICU and presented with PNA were significant predictors of neonatal mortality.

Moreover, the majority of newborn deaths resulted from preventable and treatable conditions such as birth asphyxia, prematurity, intrapartum associated factors and neonatal infections. Thus, health care providers should give due attention for neonates admitted to neonatal intensive care units by taking vital signs routinely such as temperature. In addition, the health facility management should strengthen the quality of cares given in neonatal intensive care units to improve the outcome of admitted patients. Finally, promotion of ANC follow ups for all pregnant women should be given focus in pastoral 
communities such as in the Afar region. Furthermore, prospective studies supplemented with qualitative methods are recommended.

\section{Abbreviations}

$\begin{array}{ll}\text { ANC } & \text { Antenatal Care } \\ \text { AOR } & \text { Adjusted Odds Ratio } \\ \text { CS } & \text { Cesarean Section } \\ \text { EDHS } & \text { Ethiopian Demographic and Health survey } \\ \text { MDG } & \text { Millennium Developmental Goal } \\ \text { NICU } & \text { Neonatal Intensive Care Unit } \\ \text { NMR } & \text { Neonatal Mortality Rate } \\ \text { PNA } & \text { Perinatal Asphyxia } \\ \text { RDS } & \text { Respiratory Distress Syndrome } \\ \text { WHO } & \text { World Health Organization }\end{array}$

\section{Declarations}

Ethical considerations and consent for participants

Ethical clearance was obtained from ethical review board (ERB) of Samara University, College of Medical and Health Sciences with Ref. №. CMHS/38/35/124/19. Then, a permission letter was written from the Regional Health Bureau to the randomly selected Hospitals. Finally, an official permission letter was obtained from each hospital to proceed with the data collection. Informed consent was not applicable for the study since the data was collected with medical chart review. Confidentiality was maintained by keeping records in a secured manner and avoiding personal identifiers.

Consent for Publication

Not applicable

Availability of data and materials

All materials and data related to this article were included and well supplemented during manuscript preparation. 
Competing interests:

The authors declare that they have no competing interests.

Funding

Not applicable.

Authors' contributions:

AW, YM and CSD conceived and designed the study. AW and YM supervised the data collection and they performed the data analysis, interpretation of data and drafted the manuscript. AW and CSD authors had critically reviewed the manuscript. All authors read and approved the final manuscript.

Acknowledgments

Authors thank Samara University, College of Medical and Health Sciences for its ethical review process. Authors also thank supervisors, data collectors and all NICU staffs for their contributions throughout this work.

\section{References}

1. WHO. Recommended definitions, terminology and format for statistical tables related to the perinatal period and use of a new certificate for cause of perinatal deaths: Modifications Recommended by FIGO as Amended October 14,1976:. Acta Dbstet Oynecoi Scand: 1977, 56:247-253.

2. WHO. Neonatal and Perinatal Mortality Country, Regional and Global Estimates. In. 20 Avenue Appia, 1211 Geneva 27, Switzerland: World Health Organization; 2006.

3. FMOH. Neonatal Intensive Care Unit (NICU) Training: Management Protocol. Addis Ababa, Ethiopia; 2014.

4. UNICEF. Levels \& Trends in Report 2018 Mortality. 3 UN Plaza, New York, 10017 USA: the United Nations Children's Fund; 2018.

5. FMoFED, FMOH. Assessing progress towards the millenium development goals: Ethiopia MDGs report 2012. Addis Ababa, Ethiopia; 2012.

6. UN. Transforming our world: the 2030 Agenda for Sustainable Development. http://wwwunorg /sustainable development/health/2015.

7. WHO. World health statistics 2016: monitoring health for the SDGs, sustainable development goals. 20 Avenue Appia, 1211 Geneva 27, Switzerland; 2016.

8. Lawn JE, Blencowe H, Oza S, You D, Lee AC, Waiswa P, et al. Every Newborn: progress, priorities, and potential beyond survival. Lancet 2014, 384(9938):189-205.

9. FMOH, JSI/E. Addressing Community Maternal and Neonatal Health in Ethiopia. Report from National Scoping Exercise and National Workshop to Increase Demand, Accesses and Use of Community Maternal and Neonatal Health Services: Addis Ababa, Ethiopia; May 2009. 
10. FMOH. National Newborn and Child Survival Strategy Document Brief Summary 2015/16-2019/20:. Addis Ababa,Ethiopia; 2015.

11. FMOH. Health Sector Transformation Plan (HSTP 2016-2020). Addis Ababa, Ethiopia: Federal Minstry Of Health; 2015.

12. FMOH. Health Sector Development Program IV (2010/11 - 2014/15) FINAL DRAFT. Addis Ababa, Ethiopia; 2010.

13. Chou D, Daelmans B, Jolivet RR, Kinney M, Say L. Ending preventable maternal and newborn mortality and stillbirths. BmJ 2015, 351(351:suppl1).

14. Bryce J, Boschi-Pinto C, Shibuya K, Black RE. WHO estimates of the causes of death in children. Lancet 2005, 365(9465):1147-1152.

15. Edward Fottrell DO, Glyn Alcock, Kishwar Azad, Ujwala Bapat, James Beard AB, Tim Colbourn, et al. Cause-specific neonatal mortality: analysis of 3772 neonatal deaths in Nepal, Bangladesh, Malawi and India. Arch Dis Child Fetal Neonatal Ed 2015;100 2015, 100:F439-F447.

16. Mehretie K., Teshome D. Institution Based Prospective Cross-Sectional Study on Patterns of Neonatal Morbidity at Gondar University Hospital Neonatal Unit, North-West Ethiopia. Ethiop J Health Sci 2016, 26(1):73-69.

17. Leta M. Diagnose at admission and factors associated with management outcome of neonate in ayder referral hospital, Northern Ethiopia: institutional based cross-sectional record review study. Journal of Pediatrics \& Neonatal Care 2019, 9(2).

18. Gurmesa Tura Debelew MFA, Alemayehu Worku Yalew. Determinants and Causes of Neonatal Mortality in Jimma Zone, Southwest Ethiopia: A Multilevel Analysis of Prospective Follow Up Study. PLOS ONE 9(9 2014, 9(9).

19. Gizaw M, Molla M, Mekonnen W. Trends and risk factors for neonatal mortality in Butajira District, South Central Ethiopia, (1987-2008): a prospective cohort study. BMC Pregnancy and Childbirth 2014, 14(64).

20. Demisse AG, Alemu F, Gizaw MA, Tigabu Z. Patterns of admission and factors associated with neonatal mortality among neonates admitted to the neonatal intensive care unit of University of Gondar Hospital, Northwest Ethiopia. Pediatric Health Med Ther 2017, 8:57-64.

21. Mekonnen T., Tenu T., Aklilu T., Abera T. Assessment of Neonatal Death and Causes among Admitted Neonates in Neonatal Intensive Care Unit of Mizan Tepi University Teaching Hospital, Bench Maji Zone, South-West Ethiopia, 2018. Clinics in Mother and Child Health 2018, 15(4).

22. Bekana K., Abebaw G., Hardeep RS., Sisay Y. Prevalence and associated factors of neonatal mortality in North Gondar Zone, Northwest Ethiopia. Ethiop J Health Dev 2012, 6(2).

23. CSA, ICF. Ethiopia Demographic and Health Survey 2016. Addis Ababa, Ethiopia, and Rockville, Maryland, USA: CSA and ICF; 2017.

24. UNICEF. Child Mortality Estimates; Country-specific neonatal mortality rate. http://datauniceforg/ 2018. 
25. Tewabe T, Mehariw Y, Negatie E, Yibeltal B. Neonatal mortality in the case of Felege Hiwot referral hospital, Bahir Dar, Amhara Regional State, North West Ethiopia 2016: a one year retrospective chart review. Ital J Pediatr 2018, 44(1).

26. Elmi Farah A, Abbas AH, Tahir Ahmed A. Trends of admission and predictors of neonatal mortality: A hospital based retrospective cohort study in Somali region of Ethiopia. PLoS One 2018, 13(9):e0203314.

27. Kolola T, Ekubay M, Tesfa E, Morka W. Determinants of Neonatal Mortality in North Shoa Zone, Amhara Regional State, Ethiopia. PLoS One 2016, 11(10):e0164472.

28. Seid SS, Ibro SA, Ahmed AA, Olani Akuma A, Reta EY, Haso TK, et al. Causes and factors associated with neonatal mortality in Neonatal Intensive Care Unit (NICU) of Jimma University Medical Center, Jimma, South West Ethiopia. Pediatric Health Med Ther 2019, 10:39-48.

29. Orsido TT, Asseffa NA, Berheto TM. Predictors of Neonatal mortality in Neonatal intensive care unit at referral Hospital in Southern Ethiopia: a retrospective cohort study. BMC Pregnancy Childbirth 2019, 19(1).

30. Aijaz N, Huda N, Kausar S. Disease Burden of NICU, at a Tertiary Care Hospital, Karachi. Journal of the Dow University of Health Sciences Karachi 2012, 6(1):32-35.

\section{Tables}

Table 1: Sociodemographic characteristics of study participants admitted in NICU from May 2015 to May 2019 $(n=391)$ 


\begin{tabular}{|c|c|c|c|}
\hline Characteristics & Response & Frequency & Percentage \\
\hline \multirow[t]{2}{*}{ Sex } & Male & 251 & 64.2 \\
\hline & Female & 140 & 35.8 \\
\hline \multirow[t]{3}{*}{ Age neonate at admission (in days) } & $\leq 6$ & 317 & 81.1 \\
\hline & $\geq 7$ & 74 & 18.9 \\
\hline & - & & \\
\hline \multirow[t]{2}{*}{ Residence of mother } & Urban & 321 & 82.1 \\
\hline & Rural & 70 & 17.9 \\
\hline \multirow[t]{5}{*}{ Age of the mother } & $15-19$ & 36 & 9.2 \\
\hline & $20-24$ & 142 & 36.3 \\
\hline & $25-29$ & 113 & 28.9 \\
\hline & $30-34$ & 67 & 17.1 \\
\hline & $>34$ & 33 & 8.4 \\
\hline \multirow[t]{5}{*}{ Number of cases admitted and year of admission at NICU } & 2015 & 39 & 10.0 \\
\hline & 2016 & 86 & 22.0 \\
\hline & 2017 & 83 & 21.2 \\
\hline & 2018 & 104 & 26.6 \\
\hline & 2019 & 79 & 20.2 \\
\hline
\end{tabular}

Table 2: Maternal health related factors in selected hospitals from May 2015 to May 2019, Afar region 


\begin{tabular}{|c|c|c|c|}
\hline Zharacteristics & Response & Frequency & Percentage \\
\hline \multirow[t]{2}{*}{ 3ravidity } & Primi gravid & 68 & 17.4 \\
\hline & Multi gravid & 323 & 82.6 \\
\hline \multirow[t]{2}{*}{ Parity } & Primi Para & 107 & 27.4 \\
\hline & Multi Para & 284 & 72.6 \\
\hline \multirow[t]{2}{*}{ ANC follow up } & Yes & 348 & 89.0 \\
\hline & No & 43 & 11.0 \\
\hline \multirow[t]{2}{*}{ Place of delivery } & Health institution & 346 & 88.5 \\
\hline & Home & 45 & 11.5 \\
\hline \multirow[t]{3}{*}{ Mode of delivery } & SVD & 328 & 83.9 \\
\hline & Assisted vaginal delivery & 33 & 8.4 \\
\hline & $\mathrm{C} / \mathrm{S}$ & 30 & 7.7 \\
\hline \multirow[t]{2}{*}{ Multiple delivery } & Yes & 27 & 6.9 \\
\hline & No & 364 & 93.1 \\
\hline \multirow[t]{2}{*}{ Jhronic medical illness } & Yes & 13 & 3.3 \\
\hline & No & 378 & 96.7 \\
\hline \multirow[t]{2}{*}{ HIV/AIDS status among tested } & Negative & 381 & 97.4 \\
\hline & Positive & 10 & 2.6 \\
\hline
\end{tabular}

Table 3: Fetal health conditions and causes of neonatal admission in NICU from May 2015 to May 2019 (n=391), Afar region, Ethiopia. 


\begin{tabular}{|c|c|c|c|}
\hline List of variables & Category of variable & Frequency & Percentage \\
\hline \multirow[t]{2}{*}{ Gestational age (in weeks) } & Preterm $(<37)$ & 92 & 23.5 \\
\hline & Term $(\geq 37)$ & 299 & 76.5 \\
\hline \multirow[t]{2}{*}{ Weight at birth (in kg) } & $<2.5$ & 117 & 29.9 \\
\hline & $\geq 2.5$ & 274 & 70.1 \\
\hline \multirow[t]{2}{*}{ Apgar score at $5^{\text {th }}$ minute } & $<7$ & 118 & 30.2 \\
\hline & $\geq 7$ & 273 & 65.9 \\
\hline \multirow[t]{2}{*}{ Resuscitation given at birth } & Yes & 270 & 69.1 \\
\hline & No & 121 & 30.9 \\
\hline \multirow[t]{2}{*}{ HIV/AIDS status of neonate } & Negative & 381 & 97.4 \\
\hline & Positive & 10 & 2.6 \\
\hline \multirow[t]{14}{*}{ Causes of neonatal admission in the NICU } & Prematurity & 92 & 23.5 \\
\hline & Very low birth weight & 10 & 2.3 \\
\hline & Low birth weight & 108 & 27.6 \\
\hline & Early onset neonatal sepsis & 171 & 43.7 \\
\hline & Late onset neonatal sepsis & 56 & 14.3 \\
\hline & Perinatal asphyxia & 24 & 6.1 \\
\hline & Respiratory distress syndrome (RDS) & 58 & 14.8 \\
\hline & Hypothermia & 23 & 5.9 \\
\hline & Hypoglycemia & 5 & 1.3 \\
\hline & Neonatal jaundice & 12 & 3.1 \\
\hline & Severe birth trauma & 13 & 3.3 \\
\hline & RVI exposed & 10 & 2.3 \\
\hline & Congenital malformation & 9 & 2.3 \\
\hline & Others* & 5 & 1.3 \\
\hline
\end{tabular}

Note: one neonate can take more than one care immediately after admission

Others $^{*}=$ Hepatitis infection ${ }^{1}$, anemia $^{2}$ and necrotizing enterocolitis ${ }^{2}$. Note: One neonate may have more than one causes of admission.

Table 4: Outcomes of admission and causes of neonatal mortality among neonates admitted in NICU from May 2015 to May 2019, Afar region, Ethiopia 


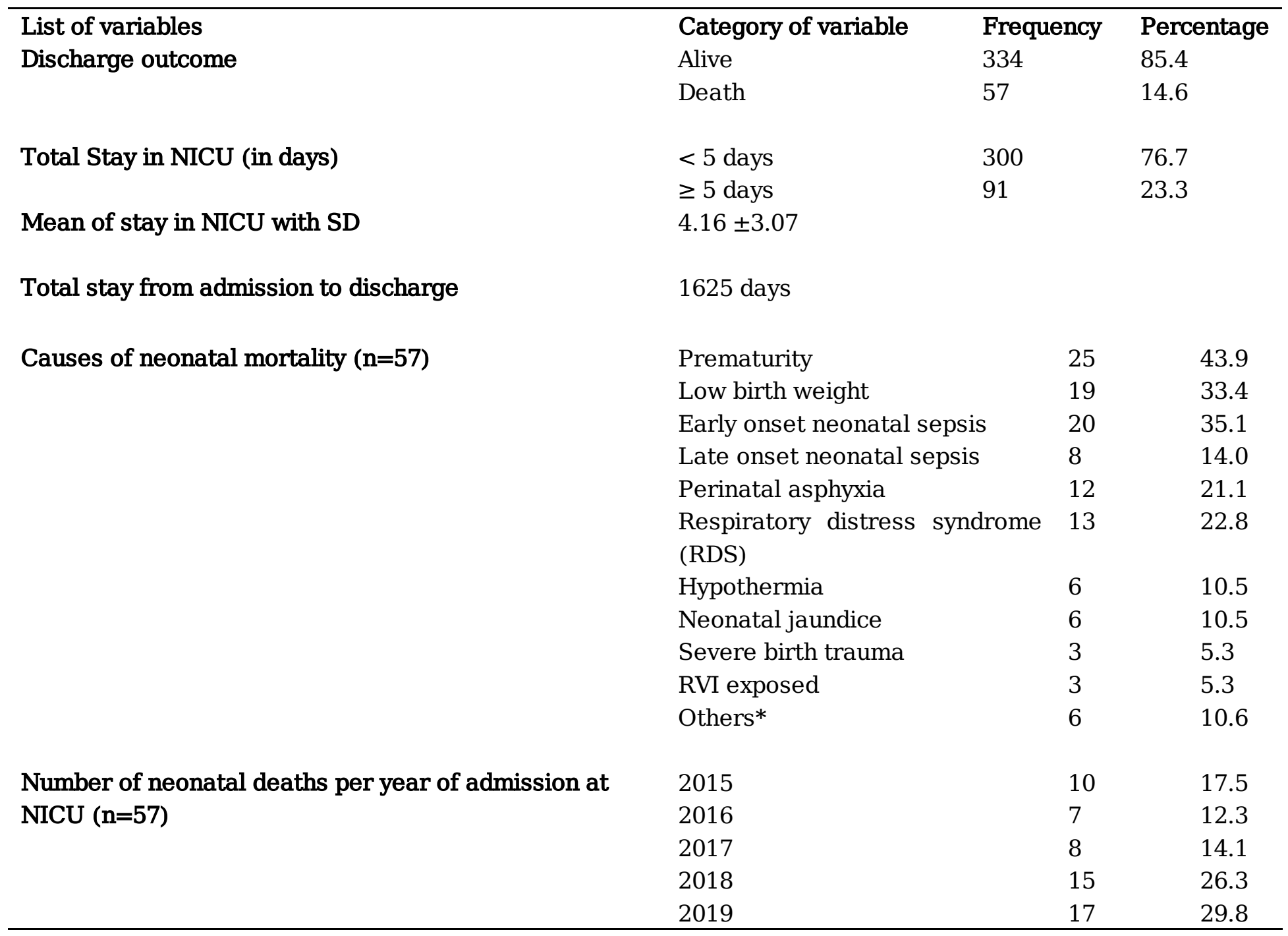

Others* $=$ NEC $^{2}$, Congenital anomalies ${ }^{1}$, anemia ${ }^{1}$, hypoglycemia ${ }^{1}$ and hyperthermia ${ }^{1}$.

Note: One neonate can have more than one cause.

Table 5: Factors associated with neonatal mortality among neonates admitted in NICUs from May 2015 to May 2019, Afar region, 2019 


\begin{tabular}{|c|c|c|c|c|c|}
\hline \multirow[t]{2}{*}{ List of variables } & \multirow{2}{*}{$\begin{array}{l}\text { Category of } \\
\text { variables }\end{array}$} & \multicolumn{2}{|c|}{ Neonatal death } & \multirow{2}{*}{$\begin{array}{l}\text { COR } \\
95 \% \mathrm{CI}\end{array}$} & \multirow{2}{*}{$\begin{array}{l}\text { AOR } \\
95 \% \mathrm{CI}\end{array}$} \\
\hline & & Yes & No & & \\
\hline \multirow[t]{2}{*}{ Sex of neonate } & Male & $42(16.7)$ & 209 (83.3) & $1.68(0.89,3.14)$ & $1.63(0.74,3.58)$ \\
\hline & Female & $15(10.7)$ & $125(89.3)$ & 1.00 & 1.00 \\
\hline \multirow[t]{2}{*}{ ANC follow up } & Yes & $41(11.8)$ & $307(88.2)$ & 1.00 & 1.00 \\
\hline & No & $16(37.2)$ & 27 (62.8) & $\begin{array}{l}4.43(2.21 \\
8.93)\end{array}$ & $\begin{array}{l}4.69 \\
(1.77,12.47) *\end{array}$ \\
\hline \multirow[t]{2}{*}{ Place of delivery } & Health institution & 47(13.6) & $299(86.4)$ & 1.00 & 1.00 \\
\hline & Home & $10(22.2)$ & $35(77.8)$ & $\begin{array}{l}1.82 \\
(0.84,3.91)\end{array}$ & $\begin{array}{l}1.44 \\
(0.48,4.29)\end{array}$ \\
\hline \multirow[t]{3}{*}{ Mode of delivery } & SVD & $40(12.2)$ & $288(87.8)$ & 1.00 & 1.00 \\
\hline & Assisted delivery & $7(21.2)$ & $26(78.8)$ & $\begin{array}{l}1.94 \\
(0.79,4.76)\end{array}$ & $\begin{array}{l}3.00 \\
(0.10,9.06)\end{array}$ \\
\hline & $\mathrm{C} / \mathrm{S}$ & $10(33.3)$ & $20(66.7)$ & $3.6(1.57,8.24)$ & $\begin{array}{l}3.59 \\
(1.22,10.55)^{*}\end{array}$ \\
\hline \multirow[t]{2}{*}{ Multiple birth } & Yes & $9(33.3)$ & 18(66.7) & $\begin{array}{l}3.29 \\
(1.40,7.75)\end{array}$ & $\begin{array}{l}2.15 \\
(0.71,6.50)\end{array}$ \\
\hline & No & $48(13.2)$ & $316(86.8)$ & 1.00 & 1.00 \\
\hline \multirow[t]{2}{*}{ 3A at birth } & Preterm & $25(26.9)$ & $68(73.1 \%)$ & $\begin{array}{l}3.06 \\
(1.70,5.50)\end{array}$ & $\begin{array}{l}1.77 \\
(0.78,4.04)\end{array}$ \\
\hline & Term & $32(10.7)$ & $266(89.3 \%)$ & 1.00 & 1.00 \\
\hline \multirow{3}{*}{$\begin{array}{l}\text { Гemperature taken at } \\
\text { 1dmission }\end{array}$} & $36.5-37.5$ & $10(7.3)$ & $127(92.7 \%)$ & 1.00 & 1.00 \\
\hline & $<36.5$ & $23(50.0)$ & $23(50.0)$ & $\begin{array}{l}12.7 \\
(5.35,30.17)\end{array}$ & $\begin{array}{l}10.75 \\
(3.75,30.80) *\end{array}$ \\
\hline & $>37.5$ & $24(11.5)$ & $184(88.5)$ & $\begin{array}{l}1.66 \\
(0.77,3.58)\end{array}$ & $\begin{array}{l}1.57 \\
(0.64,3.82)\end{array}$ \\
\hline \multirow[t]{2}{*}{ PNA } & Yes & $11(45.8 \%)$ & $13(54.2 \%)$ & $\begin{array}{l}5.9 \\
(2.50,13.96)\end{array}$ & $\begin{array}{l}7.16 \\
(2.22,23.10) *\end{array}$ \\
\hline & No & $46(12.5 \%)$ & $321(57.5 \%)$ & 1.00 & 1.00 \\
\hline \multirow[t]{2}{*}{ RDS } & Yes & $5(38.5 \%)$ & $8(61.5 \%)$ & $\begin{array}{l}3.92 \\
(1.23,12.44)\end{array}$ & $\begin{array}{l}1.60 \\
(0.32,8.03)\end{array}$ \\
\hline & No & $52(13.8 \%)$ & $326(86.2 \%)$ & 1.00 & 1.00 \\
\hline \multirow[t]{2}{*}{ Length of stay } & $<5$ days & $50(16.7 \%)$ & $250(83.3 \%)$ & 1.00 & 100 \\
\hline & $\geq 5$ days & 7 (7.7\%) & 84(92.3\%) & $\begin{array}{l}0.417 \\
(0.18,0.95)\end{array}$ & $\begin{array}{l}0.231 \\
(0.08,0.66)^{*}\end{array}$ \\
\hline
\end{tabular}

Key: ${ }^{*}=\mathrm{P}<0.05, \mathrm{COR}=$ Crude Odds Ratio, AOR=Adjusted Odds Ratio, C/S=Cesarean Section, SVD= Spontaneous Vaginal Delivery, RDS= Respiratory Distress Syndrome, PNA= Perinatal Asphyxia 
Figures

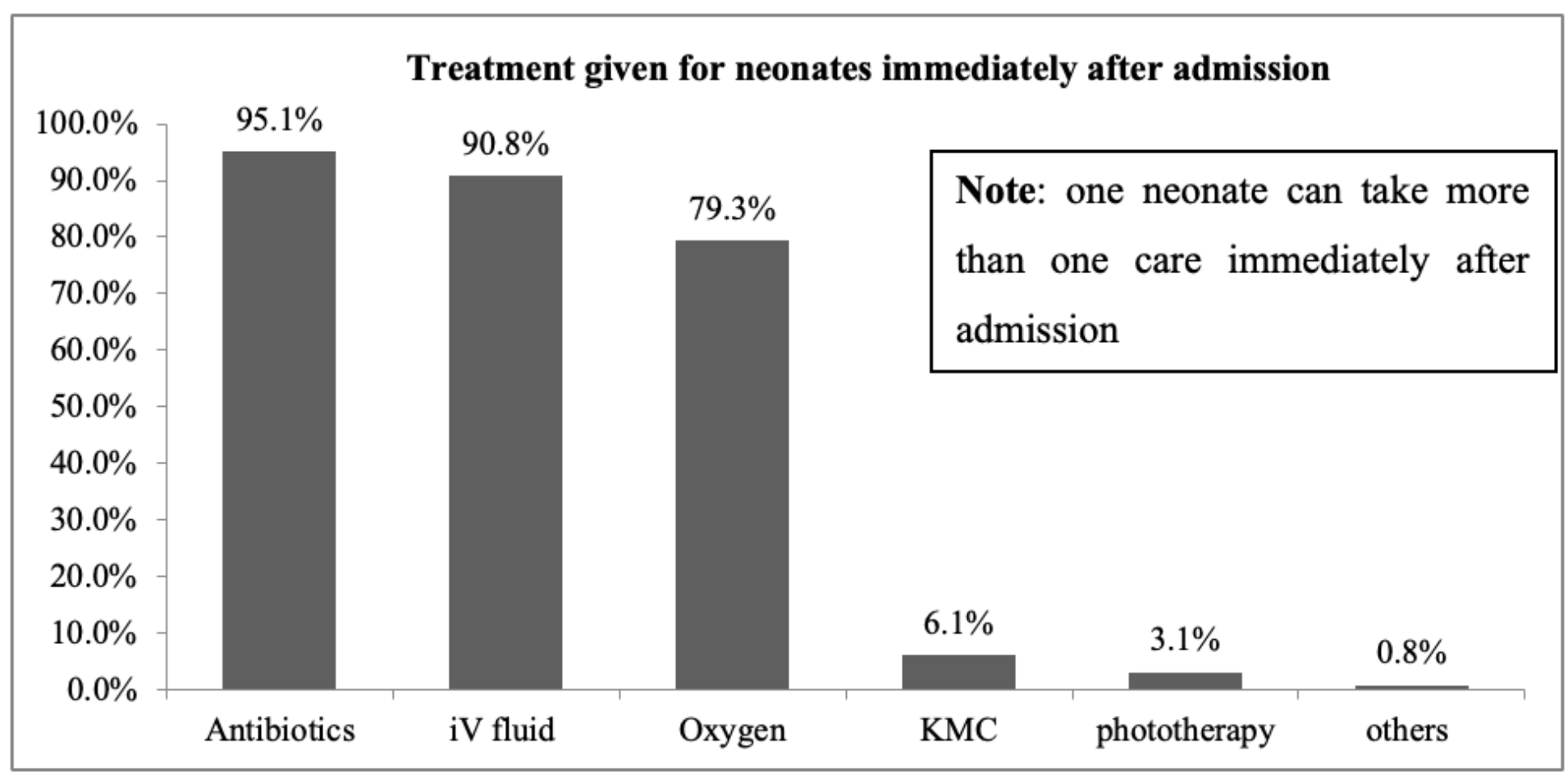

Figure 1

Cares given for neonates admitted in NICU from May 2015 to May 2019, Afar, Ethiopia 